\title{
生涯教育 “一对一”一促进学生全面而有个性发展
}

张洁

河北省期部市第四中学

DOI:10.32629/er.v2i12.2230

[摘 要] 高考改革有序推进,新的招生考试模式要求学校兼顾学生的全面发展与个性化培养,这也为各个学校的生涯教育提出了更高的要求。 新高考下,都郸市第四中学南校区积极落实改革要求,结合学生实际,整合校内外资源,构建了“1254”生涯教育课程体系,同时针对学生个体性差 异深入探索,开启生涯教育“一对一”指导,力促学生的个性化、专业化发展。

[关键词] 学生; 生涯教育; 一对一指导

高中生涯教育关注的是全体学生的生涯发展, 有其高中阶段普遍性规 律。邯郸四中南校区在 “ 1254 ” 生涯教育课程体系下, 开展以班级为单位 的生涯规划课、主题班会, 以年级为单位的青春大讲堂、社团、社会实践 等活动, 同学们积极参与, 在相关课程及实践中对生涯的认知开始初步明 晰, 对未来的发展有了初步思考。然而, 教育实践中我们深刻认识到, 学生 有着鲜明的个体性, 要让生涯教育收到实效, 就必须尊重学生的个性特长, 通过个体生涯指导, 实现学生全面而有个性的发展。

\section{1 实施背景}

前苏联著名教育家苏霍姆林斯基说: “每个学生都是一个独一无二的 世界。”事实上, 每个学生都是一个具有自己特点、才能、兴趣爱好、命运、 生活任务的人, 我们能做到的只是通过生涯教育的帮助使他们学会自己制 定一个适合他的生涯规划。 ${ }^{[1]}$ 每个人都有着独一无二的生涯, 每个学生的 成长背景、性格特征、学习基础、爱好兴趣、生命潜能等都不一样, 要让 生涯教育收到实效, 就必须尊重学生的个性特长, 通过个体生涯指导, 实现 学生全面而有个性的发展。

\section{2 实施路径}

美国学者舒伯认为, 不同阶段有不同的生涯发展任务, 高中阶段正处 在生涯发展的探索期, 这一时期是个人认真探索各种可能职业选择的黄金 时期。生涯教育是引导学生在不断探索发现、构建自我的过程中创造出一 种适合个体的、有目的的、连续不断的生活模式, 过一种有意义的人生。 而作为生涯 “试探期 (15-18岁)” 的高中阶段, 主要任务就是认识自我、认 识社会、认识高校和专业等, 在考虑个人需要、兴趣、能力与机会基础上, 形成暂时性决定, 不断地考虑可能从事的职业领域和工作层次, 并把职业 偏好逐渐具体化。高中的生涯教育要让高中生意识到个体一生的变化发展, 认识到社会对于人才需求的变化特点, 明确如何将当下的自己放到人的一 生和社会大环境中思考和规划未来发展之路。

在 “1254” 生涯课程体系的基础上, 学校探索实施 “一对一” 生涯指 导, 力求能围绕高中生涯教育的特点, 结合学生个体特点, 为学生量身定制, 使之找到人生的目标和职业方向, 认识自我、塑造自我, 解决学生的具体困 难, 增强生涯教育的针对性、有效性。

邯䣋四中南校区 “生涯教育一对一指导” 在2018级试点先行, 实行预 约制。每周固定时间, 年级协调安排两到三名学生, 由学生发展中心专职生 涯教师接待约访, 提供个性化、面对面、一对一的咨询服务。生涯专职教 师与学生进行互动沟通, 梳理解决学生目前生涯认知、学业规划、职业困 惑、选课走班、志愿填报等方面的问题, 帮助他们科学认知自我, 合理规划 人生, 增强就业指导与服务工作的针对性和有效性, 从而促进学生成才与 就业。

\section{3 实施策略}

3. 1 横向无缝式一对一

在与师生的访谈中我们发现, 学生在自我认知、科目选择、职业规划、 选科走班、高考新政、志愿填报等方面具有一定的盲目性, 几个比较集中 的问题: 一是没方向, 不清楚自己到底要什么; 二是自我认知贵乏, 不知道 自己的情趣爱好、性格潜能是什么; 三是选择纠结, 不知道如何选课、如 何选专业; 四是不清晰, 对于未来发展、国际形势没有科学认识等。这些 问题如果能及时解决, 将使学生的高中学习生涯更有目的性、针对性, 从而 有效促进学生的科学化、个性化、可持续发展。

根据调研情况, 学校从自我认知、选科走班、学业规划、心理咨询、 职业规划、志愿填报等方面, 来实现横向的无缝式全面指导。

一是自我认知一对一。老子说过: “知人者智也, 自知者明也。在生 涯规划过程中, 学生首先应该根据自身情况做出客观且全面的自我分析, 结合学生兴趣、能力、个人特质、价值观等, 教会学生认识自我的方法, 进行性格、兴趣、爱好、潜能等的探索, 引导学生客观、理性地审视自己, 实现自我认知, 开始比较清晰的去思考未来。

二是选科走班一对一。在河北新高考 $3+1+2$ 模式大背景下, 选科是学生 面临的新课题, 科学选科有助于拓展学生的知识与技能, 发展学生的兴趣 和特长, 培养学生的个性, 帮助学生获得与自己 “匹配” 的教育。在详细解 读高考新政基础上, 结合高校招生需求、社会经济形势、职业现状等情况, 充分尊重学生个性特质, 从学科优势、学科兴趣、个性发展、生涯规划等 方面梳理出学生的选科理由, 力求精准定位, 帮助学生确定适合自己的选 科模式。

三是学业规划一对一。高中生学业规划是生涯规划的基石。让学生认 清高中各个阶段的学习特点, 帮助其制定适合自己的各阶段学习计划, 引 导其掌握各学科的学习方法, 指导学生做好时间管理, 建立高效自主的的 自我的学业发展之路。

四是心理咨询一对一。高中阶段学生不可避免会存在的心理健康问 题: 学习方面, 如学习压力大、厌学、考试焦虑等; 人际关系方面, 如与教 师、与同学、与父母相处时出现的问题; 青春期心理问题, 如青春期闭锁 心理, 早恋, 情绪情感激荡、表露而又内隐等。学校学生发展中心的心理教 师会通过与学生的沟通交谈进行科学诊断, 依据问题的需要使用适当的心 理治疗方法, 减轻或消除学生的不适应的心理现象及行为, 促进其心理的 健全发展。

五是职业规划一对一。职业生涯规划一般要经历五个步骤: 自我认知 与职业调研、职业生涯机会综合评估、职业生涯目标确定、职业生涯策略 研究、职业生涯规划调整。鉴于学生的生涯目标比较盲目, 学校引入相关 职业探究, 梳理职业信息, 结合学生特质、职业特点以及学生个性与职业的 有效融合等方面进行科学分析, 引导学生初步确立自己的职业生涯发展目 
标。清晰并且可实现的生涯发展目标描述, 是职业生涯成功的关键因素之 一, 目标越明确越有激励作用, 将对学生的高中阶段学习带来重要的正向 影响。

六是填报志愿一对一。高考志愿选择是莘莘学子的重要转折期, 虽然 不能决定一个人最终的职业去向与生活质量, 但是在很大程度上影响了一 个人在大学时期的专业积累, 以及对未来的职业思考。 ${ }^{[2]}$ 向学生阐明高考 志愿决策的基本原则和策略, 即以自己的分数选择最合适的专业, 在所定 专业上选择最有办学优势、并且最有可能被录取的学校。具体说, 第一步 是获取信息, 第二步是搜集情报, 第三步是如何选, 这个是关键。针对学生 的高考成绩和个体特质, 结合当前大学专业特点、历年录取情况及就业形 势等, 向学生作科学建议, 使之能进入最适合自己的大学去就读深造, 实现 人生价值最大化。

3.2纵向阶梯式一对一

高中生具有可塑性, 发展空间大, 在高中阶段的职业生涯规划主要是 明确三年的具体学习计划和规划未来的发展方向。一般来说, 每一个年级, 学生所面临的规划重点不同, 因此, 对他们的生涯指导着力点也是不一样 的, 学校以纵向阶梯式策略来进行指导。

高一年级学业规划。“学业规划” 的目标是在学生初步完成未来专业 方向选择的基础上, 指导学生完成高中学科课程计划, 做好未来高考和高 等教育学习的课程和学业成果规划准备。一对一指导的内容主要包括 “选 科指导” 和 “学科学习规划指导”。“选课指导” 是学业规划课程的核心内 容, 可以让学生明确未来高考专业方向, 完成高中三年课程的选课安排, 制 定课程初步计划。完成课程选择后, 对学生进行 “学科学习规划指导”, 初步确定高中学习领域和项目的方向。

高二年级职业规划。“职业规划” 课程是结合学生选择专业方向和重 点学科的安排, 增强学科知识与学科应用的结合, 增强学生创新精神和实 践能力, 为高考和大学持续学习奠定基础。一对一指导的主要内容包括“学 科领域深入研究” 和 “学科学习方法指导”, 增强学生对自己未来职业方 向的了解。

高三年级人生规划。“人生规划”课程通过指导学生志愿填报实现学 业与职业、事业的链接, 同时辅助心里疏导, 建立积极的生活态度和人生目 标, 为人生持续发展、幸福生活奠定心理基础。在一对一指导中, 一方面, 就学生志愿填报进行理论和技术指导; 另一方面结合心理辅导的手段方法, 对学生进行备考阶段的心理疏导, 提升学生对未来发展的信心。

3. 3立体交互式一对一

立体交互式一对一, 就是结合专业特点、学生实际, 有效地运用各种教
学手段, 实现教师、学生、实践环节多主体相互关联、相互融合的一对一 指导。指导中, 采取更多的方式和策略, 如交互式游戏、主题探索、现场实 作、角色扮演、亲师合作、分享、访问晤谈、表演等, 提高学生兴趣, 提升 指导效果。

具体工作中要注意以下三个 “相统一”。一是 “小我” 和 “大我” 的 统一。在职业选择和发展中, 学生应跳出 “小我” 的圈子, 把自身能力和社 会需要相统一, 把 “小我” 和 “大我” 相统一。二是 “职业理想” 和 “社 会现实” 的统一。理想和现实的统一, 就是把学生自己的主观愿望同社会 实践活动相统一、把对社会的主观判断同社会实际情况相统一。三是 “规 划职业” 与 “人格完善” 的统一。高中学生的职业规划具有德育和完善人 格的意义, 使学生在高中阶段就思考现在与未来、自我与社会的关系, 参与 社会实践, 承担社会责任。

交互式指导, 使学生学会在实践环节中发现自身的不足, 在逆境中体 会真实的痛感, 在解决问题中享受成功的喜悦, 在实践中学会体谅、分享, 学会互助、共赢, 学会忍受与坚持, 学会独立与承担。

\section{4 实施效果}

邯部四中南校区生涯教育 “一对一” 指导实践, 着重落实学生生涯规 划三个方面的能力: 一是自我探索能力, 指导学生了解自己, 认识自我; 二 是生涯探索能力, 指导学生认识自身学习境况和未来职业世界; 三是生涯 管理能力, 指导学生学习生涯规划、生涯决策及调适等。

加强生涯教育指导, “有利于学生科学设计自己的未来发展”, “为 不同类型学生个性发展引航”, “是为了每一个学生的终身发展教育理 念的体现。” ${ }^{[3]}$ 学校通过生涯教育 “一对一” 指导, 让每一个学生找到方 向, 拥有独一无二的最适合自己的规划, 进而生成努力奋进的内驱动力, 踏实地走好每一步人生道路, 构建自己热爱的人生, 这也是生涯教育的 意义所在。

\section{[参考文献]}

[1]徐鹏.生涯发展教育浅析[J].科技致富向导,2014(27):314。

[2] 李炎.浅议高中生职业生涯教育探索 [J]. 教育教学论 坛,2015(16):25-26.

[3]杨泰山。中学生生涯发展指导的重要意义[J]. 大众心理 学,2014(9):18-19.

\section{作者简介：}

张洁(1982--),女,汉族,河北省期郸市人,新加坡南洋理工大学教 育管理硕士,中学一级教师,国家二级心理咨询师。研究方向：高中生 涯教育。 